\title{
A Modified Perturb and Observe Sliding Mode Maximum Power Point Tracking Method for Photovoltaic System uUnder Partially Shaded Conditions
}

\author{
Jehun Hahm ${ }^{1}$, Euntai Kim ${ }^{2}$, Heejin Lee ${ }^{3}$, and Changyong Yoon ${ }^{4}$ \\ ${ }^{1}$ Disaster Robotics R\&D Center, Korea Institute of Robot Convergence, Pohang, 37666, Korea \\ ${ }^{2}$ Department of Electrical and Electronic Engineering, Yonsei University, Seoul, Korea \\ ${ }^{3}$ Department of Electrical, Electronic and Control Engineering, Hankyong National University, Ansung, \\ Korea \\ ${ }^{4}$ Department of Electrical Engineering, Suwon Science College, Hwaseong, Korea
}

\section{]jfis}

\begin{abstract}
The proposed scheme is based on the modified perturb and observe $(\mathrm{P} \& \mathrm{O})$ algorithm combined with the sliding mode technique. A modified $\mathrm{P} \& \mathrm{O}$ algorithm based sliding mode controller is developed to study the effects of partial shade, temperature, and insolation on the performance of maximum power point tracking (MPPT) used in photovoltaic (PV) systems. Under partially shaded conditions and temperature, the energy conversion efficiency of a PV array is very low, leading to significant power losses. Consequently, increasing efficiency by means of MPPT is particularly important. Conventional techniques are easy to implement but produce oscillations at MPP. The proposed method is applied to a model to simulate the performance of the PV system for solar energy usage, which is compared to the conventional methods under non-uniform insolation improving the PV system utilization efficiency and allowing optimization of the system performance. The modified perturb and observe sliding mode controller successfully overcomes the issues presented by non-uniform conditions and tracks the global MPP. Compared to MPPT techniques, the proposed technique is more efficient; it produces less oscillation at MPP in the steady state, and provides more precise tracking.
\end{abstract}

Keywords: Photovoltaic generator, Partial shaded, PEMFC, Maximum power point tracking (MPPT), Perturb and observe (P\&O), Incremental conductance (IncCond)

Received: Nov. 21, 2016

Revised : Dec. 12, 2016

Accepted: Dec. 13, 2016

Correspondence to: Changyong Yoon

(cyyoon@ssc.ac.kr)

(The Korean Institute of Intelligent Systems

cCThis is an Open Access article distributed under the terms of the Creative Commons Attribution Non-Commercial License (http://creativecommons.org/licenses/ by-nc/3.0// which permits unrestricted noncommercial use, distribution, and reproduction in any medium, provided the original work is properly cited.

\section{Introduction}

Recent environmental catastrophes and controversies over the energy resource of fossil resources have elicited vast, active research into source of energy that are clean and cause less environmental contamination [1]. Photovoltaic (PV) and fuel cells, consequently, have been widely pursued as renewable energy saving technologies because they do not produce environmental pollution, and are abundant and widely available [2]. Renewable energy sources and energy-saving technologies have been researched as methods to resolve the problems of the energy crunch and global warming. Among renewable energy technologies, the importance of PV systems and proton exchange membrane fuel cells (PEMFCs) is significantly increasing because of their advantage of environmental contamination free operation, low noise, and 
minimal maintenance requirements [1]. Renewable energy technologies are growing swiftly, at an annual average of $40 \%$ over the last decade [3].

To provide alternating current (AC) power from the PEMFC and the PV system to the grid, which is at 220-240 Vrms in most countries, a power interface is required. PV and PEMFC energy systems have various applications, including in green household appliances [4-6], in solar vehicle [7] and fuel cell vehicle [8] for distant military missions [9], and even for electric ships and aircrafts [10, 11]. The brushless direct current (BLDC) motor is a promising companion technology that has been used extensively in many industrial applications owing to its high performance in terms of power factor, operation life, efficiency, control simplicity, and maintainability, torque, speed [12, 13].

From the point of view of evaluation, the output voltage of a PV cell can vary greatly under a variety of weather conditions, which can result in control problems. Under suddenly changing weather conditions, it is difficult to keep track of the change of result in PV output power [14, 15].

One way to overcome these problems is to employ a PV power generation system hybridized with other power sources such as battery energy storage systems, diesel generator systems, and fuel cell systems. Battery energy storage systems can be charged or discharged depending on the insolation [1, 6,, 16 17].

The paper is organized as follows: the proposed Modified Perturb and observe ( $\mathrm{P} \& \mathrm{O})$ sliding mode maximum power point tracking is presented in Section 2; modelling of the PV system and the power output of a partially shaded PV array are described in Section 3; simulation results for the different MPPT algorithms with partially shaded PV modules with a focus on variations in insolation and temperature are described in Section 4; and we present conclusions in Section 5.

\section{Modified Perturb and Observe (P\&O) Slid- ing Mode Maximum Power Point Tracking}

The MPPT algorithms resulted in oscillations of the position of the MPP which can actually lead it away from its optimal value. In order to overcome this drawback, an analysis is provided to understand the expected displacement of the operating point resulting from an applied perturbation of the operating conditions [1, 2, 6, 18, 19]. Figure 1 illustrates the scheme of the modified perturb and observe sliding mode technique.

Four cases of perturbations from the operating point can be distinguished:

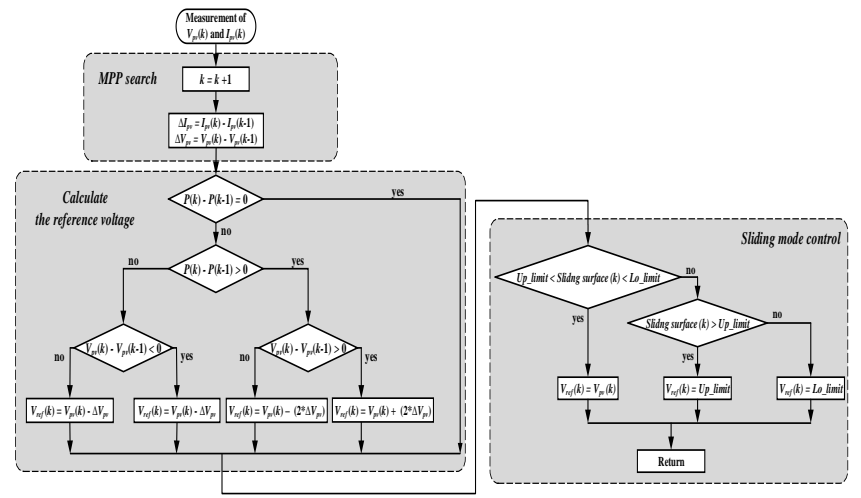

Figure 1. Flowchart of the proposed modified $\mathrm{P} \& \mathrm{O}$ algorithm.

First case (Figure 2(a)) : After the perturbation, there is a displacement of the operating point from $k-1$ to $k$, with $P(k)>P(k-1)$ and $V(k)>V(k-1)$. The power increases after the perturbation. This indicates that the MPP search is oriented in the right direction. The search of operating point $k+1$ by increasing the duty cycle by $\Delta d$. The voltage is then increased to $V(k+1)=V(k)+\Delta v$.

Second case (Figure 2(b)) : After the perturbation, there is a displacement of the operating point from $k-1$ to $k$, with $P(k)<P(k-1)$ and $V(k)<V(k-1)$. The power decreases after the perturbation. This indicates that the MPP search is oriented in the wrong direction. The MPP search direction must be changed and the duty cycle is increased by $2 \Delta d$ to reach the operating point $k+1$. The voltage is then increased to $V(k+1)=V(k)+2 \Delta v$.

Third case (Figure 2(c)) : After the perturbation, there is a displacement of the operating point from $k-1$ to $k$ so that $P(k)>P(k-1)$ and $V(k)<V(k-1)$. The power increases after the perturbation. This indicates that the MPP search is oriented in the good direction. Then, the MPP search direction must be maintained and the duty cycle is decreased by $\Delta d$ to reach the operating point $k+1$ [20]. The voltage is then decreased to $V(k+1)=V(k)-\Delta v$.

Fourth case (Figure 2(d)) : After the perturbation, there is a displacement of the operating point from $k-1$ to $k$ so that $P(k)<P(k-1)$ and $V(k)>V(k-1)$. The power decreases after the perturbation. This indicates that the MPP search is oriented to bad direction. Then, the MPP search direction must be changed and the duty cycle is increased by $2 \Delta d$ to reach the operating point $k+1$. The voltage is then decreased to $V(k+1)=V(k)-2 \Delta v$. 


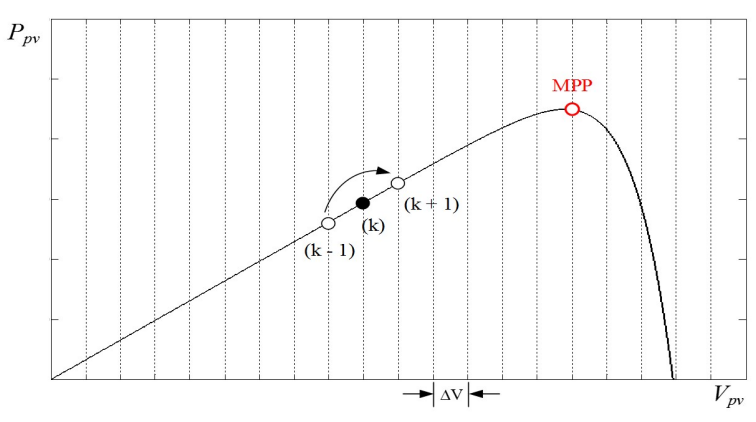

(a)

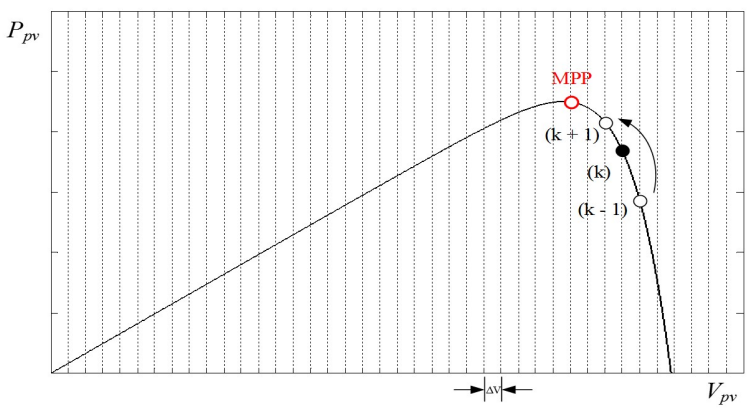

(c)

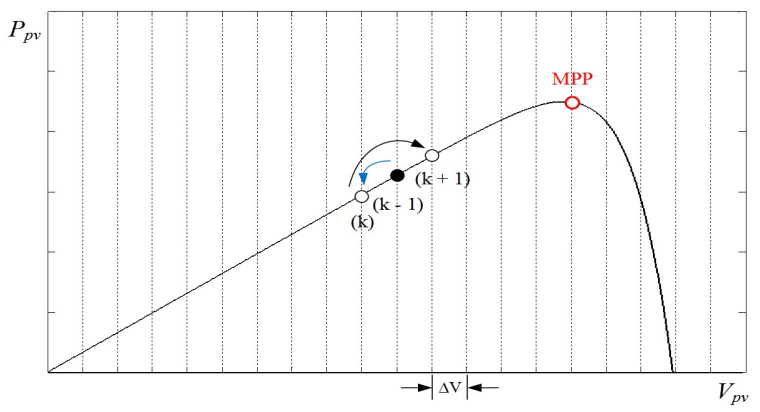

(b)

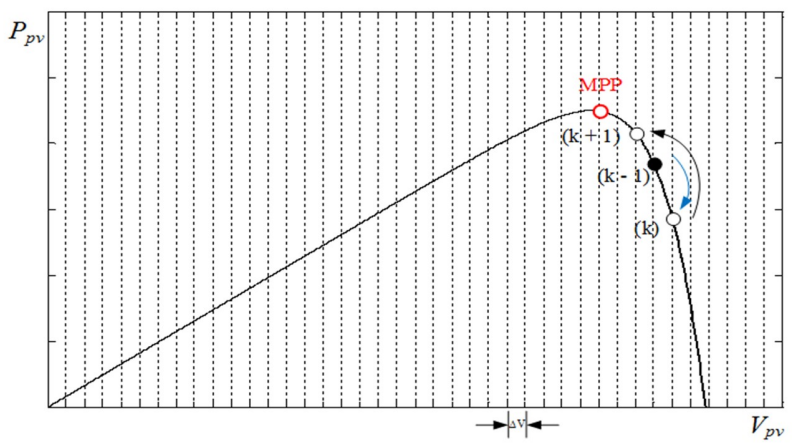

(d)

Figure 2. Various cases of displacement of the operating point. (a) First case, (b) second case, (c) third case, and (d) fourth case of operation.

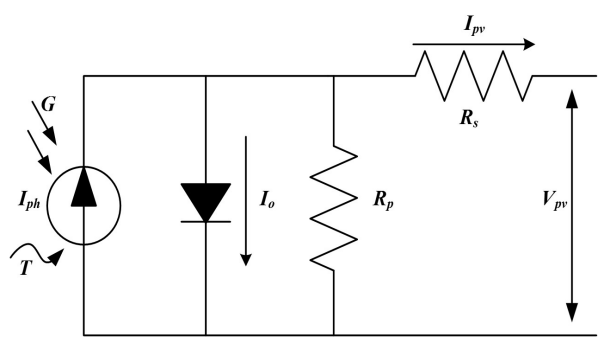

Figure 3. Equivalent circuit model of a PV cell.

\section{Photovoltaic Generator System}

The PV array consists of a number of cells connected in series or in parallel; The output and light-induced electromotive current can be written as follows [21-23]:

$$
I_{o}=I_{p v}-I_{d}-I_{p},
$$

where $I_{o}$ is the PV output current, $I_{p v}$ is the light-generated current, $I_{d}$ is the diode current, and $I_{p}$ is the parallel resistance current.

Light-generated current is a function of temperature and insolation and is given by

$$
I_{p v}=I_{s c r} \frac{R}{R_{r e f}}+K_{i}\left(T-T_{r e f}\right),
$$

where $I_{s c r}$ is the cell short-circuit current; $R$ and $R_{r e f}$ are the input insolation and reference insolation, respectively; $T$ and $T_{r e f}$ are the cell temperature and the reference temperature in Kelvin, respectively; and $K_{i}$ is the short-circuit current temperature coefficient.

Then, the diode current, which is a function of the saturation current, can be written as

$$
I_{d}=I_{\text {sat }}\left\{\exp ^{\frac{q\left(V_{o}+I_{o} R_{s}\right)}{A k T}}-1\right\}
$$

where $I_{\text {sat }}$ is the diode saturation current, $R_{s}$ is the series resistance, $k$ is the Boltzmann constant $\left[1.3805 \times 10^{-23} \mathrm{~N} \cdot \mathrm{m} / \mathrm{K}\right]$, and $q$ is the electron charge $\left[1.6021 \times 10^{-19} \mathrm{C}\right]$.

Furthermore, the parallel resistance current gives a measure of the PV cell loss; it can be calculated as follows:

$$
I_{p}=\left(\frac{V_{o}+I_{o} R_{s}}{R_{p}}\right),
$$


Table 1. Specifications of the KC200GT solar module at $25^{\circ} \mathrm{C}, 1,000$ $\mathrm{W} / \mathrm{m}^{2}$ from the datasheet [2]

\begin{tabular}{cc}
\hline Designation & KC200GT \\
\hline Maximum power $\left(P_{\max }\right)$ & $200.143 \mathrm{~W}$ \\
\hline Voltage at maximum power $\left(V_{m p}\right)$ & $26.3 \mathrm{~V}$ \\
Current at maximum power $\left(I_{m p}\right)$ & $7.61 \mathrm{~A}$ \\
Open circuit voltage $\left(V_{o c}\right)$ & $32.9 \mathrm{~V}$ \\
Short circuit current $\left(I_{s c}\right)$ & $8.21 \mathrm{~A}$ \\
\hline Temperature coefficient of $V_{o c}\left(K_{V}\right)$ & $-123 \mathrm{mV} /{ }^{\circ} \mathrm{C}$ \\
Temperature coefficient of $I_{s c}\left(K_{I}\right)$ & $3.18 \mathrm{~mA} /{ }^{\circ} \mathrm{C}$ \\
Number of cells $\left(N_{s}\right)$ & 54 \\
\hline
\end{tabular}

where $R_{p}$ is the parallel resistance.

Finally, the saturation current varies as a function of temperature and can be expressed as

$$
I_{\text {sat }}=I_{\text {satr }}\left(\frac{T}{T_{\text {ref }}}\right)^{3} \exp \left\{\frac{q E_{g}}{B k}\left(\frac{1}{T_{R}}-\frac{1}{T_{C}}\right)\right\},
$$

where $I_{\text {satr }}$ is the reference cell saturation current, $T_{r e f}$ is the ideality factor, and $E_{g}$ is the cell band gap energy.

By using the equivalent circuit of a single diode model as shown in Figure 3, the generated current can be expressed as:

$$
I_{o}=N_{p}\left[I_{p v}-I_{d}\left\{e^{\frac{q\left(V_{o}+R_{s} I_{o}\right)}{A k T N_{s}}}-1\right\} \frac{V_{o}+R_{s} I_{o}}{N_{s} R_{p}}\right],
$$

where $A$ is a dimensionless junction material factor, $N_{p}$ and $N_{s}$ are the numbers of cells connected in parallel and series, respectively.

The PV module type is KC200GT, and its specifications are reported in Table 1.

With reference to Figure 4, the PV characteristics is nonlinear in response to changes in solar insolation and temperature. Figure 4(a) shows characteristic $I-V$ curves of a PV array for various values of constant insolation; as the insolation increases, the open-circuit voltage and short-circuit current of the PV cell both increase. Similarly, Figure 4(b) depicts characteristic $I-V$ curves of a PV array for various constant temperatures. Figure 5(a) shows characteristic $P-V$ curves of a PV array for various values of constant insolation; as the isolation increases, the open-circuit voltage and short-circuit current of the PV cell both increase. Similarly, Figure 5(b) depicts characteristic $P-V$ curves of a PV array for various constant temperatures. Note that as the temperature increases, the characteristic short-circuit current increases slightly and the open-circuit voltage decreases.

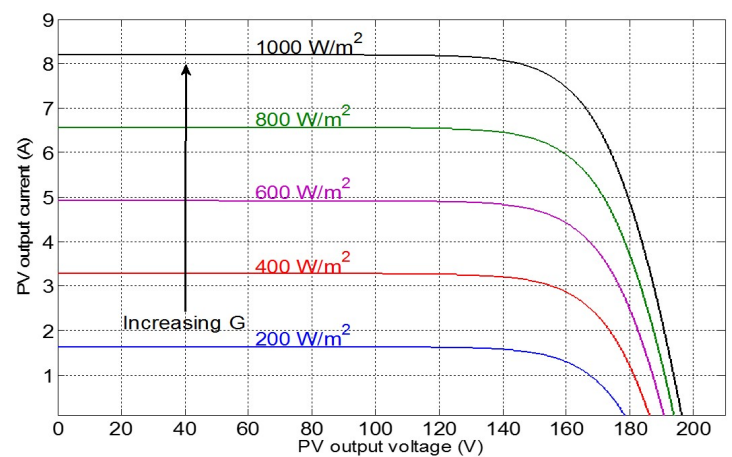

(a)

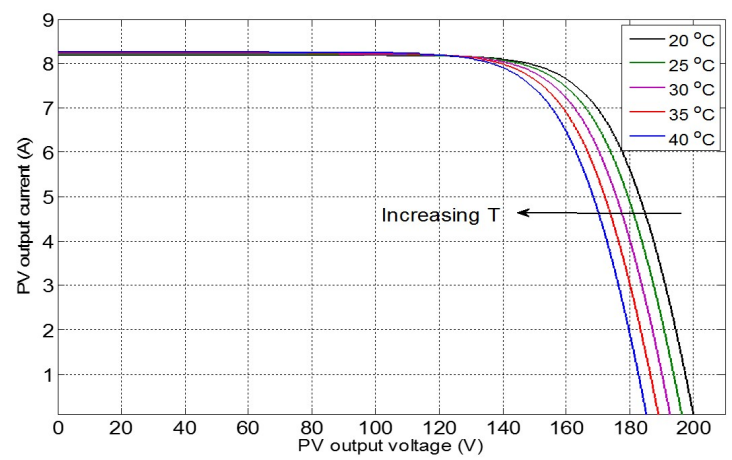

(b)

Figure 4. Influence of the $I-V$ characteristics. (a) Constant uniform insolation condition $(\mathrm{G})$ and $(\mathrm{b})$ constant uniform temperature conditions $(\mathrm{T})$.

Four cases of partially shaded PV modules were also investigated, as reported in Figure 6. Under full insolation, the $P-V$ characteristic had one peak; however, when partial shading of the PV modules occurred, multiple peaks existed. The characteristic $I-V$ curves of the PV array system shown in Figure 6 depend on the insolation of the PV system. However, insolation is not equally distributed to partially shade the PV module. The following three cases of partially shaded PV modules are considered.

Case (i): one module is shaded with unequal insolation (i.e., PV module 1).

Case (ii): two modules are partially shaded with unequal insolation (i.e., PV modules 1 and 2).

Case (iii): two modules are partially shaded with unequal insolation (i.e., PV modules 1 and 3).

Case (iv): three modules are partially shaded with different insolation (i.e., PV modules 1, 2, and 3).

The simulation results for the four cases suggest that a partially shaded module causes a reduction in PV output power. 


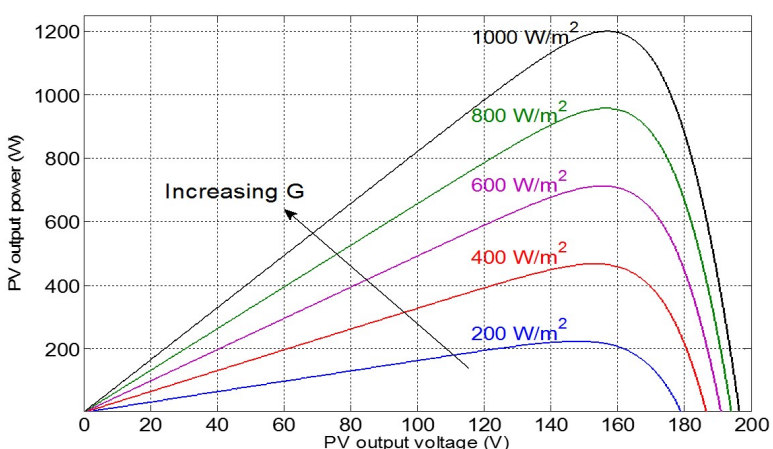

(a)

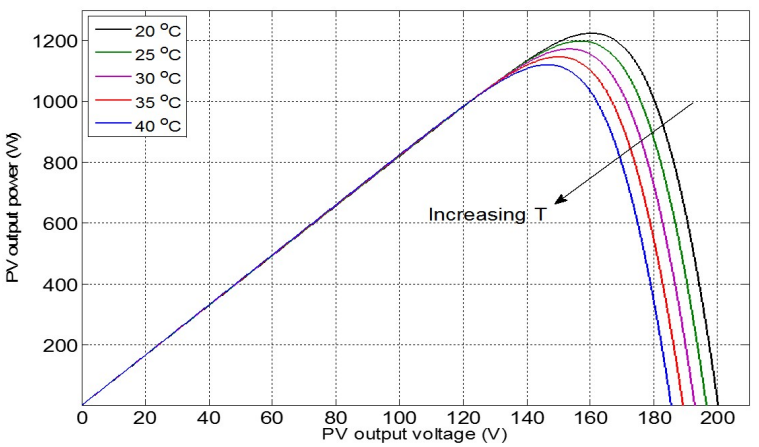

(b)

Figure 5. Influence of the $I-V$ characteristics. (a) Constant uniform insolation condition $(\mathrm{G})$ and $(\mathrm{b})$ constant uniform temperature conditions ( $\mathrm{T}$ ).

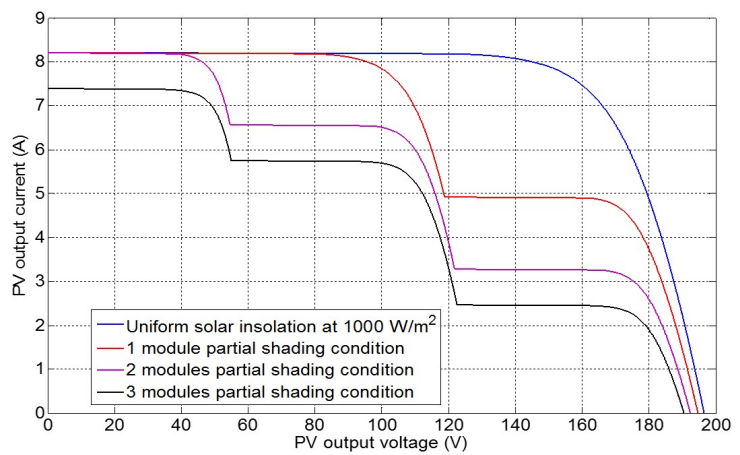

Figure 6. PV output power characteristics under different partial shade conditions (three cases).

This information is further illustrated in Figure 7 where the $\mathrm{x}$-axis represents the time of day, the y-axis shows the month of a year, and the $\mathrm{z}$-axis indicates the amount of irradiation received during these times.
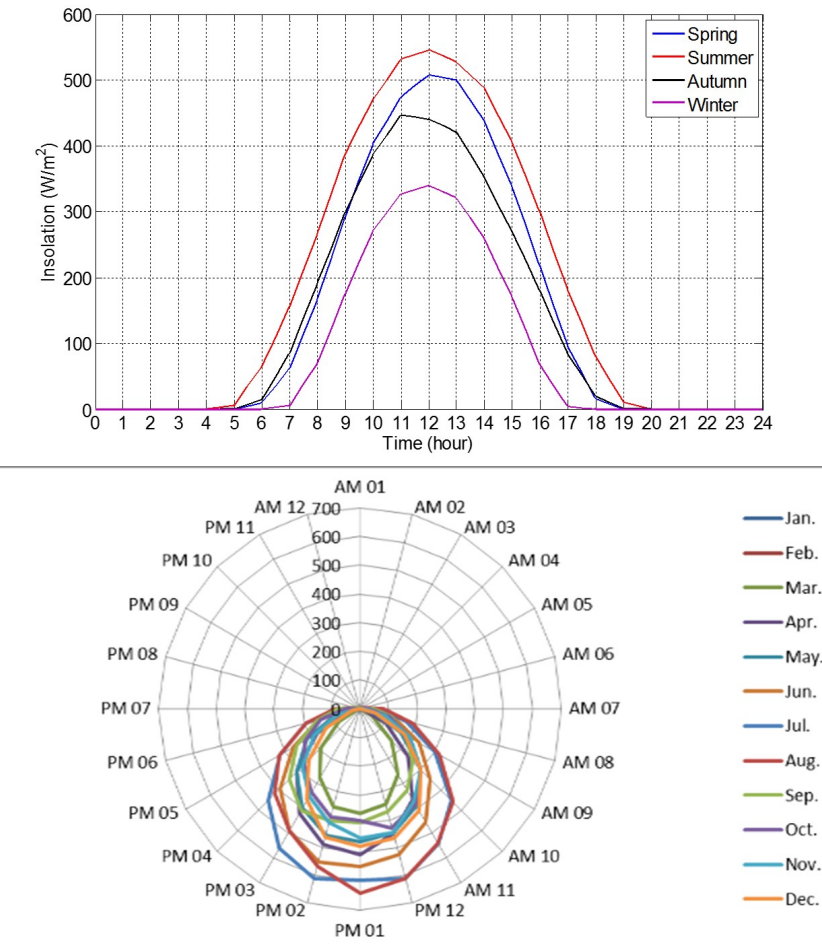

Figure 7. Summarizes the average irradiation data for approximately each hour of sun exposure over the course of a year in Korea.

\section{Results and Discussion}

The tests used to compare the five algorithms under nonuniform insolation and temperature conditions are described in Section 4.1. Comparative simulation results are discussed in Section 4.2 .

\subsection{Response of the Different MPPT Techniques to Nonuni- form Weather Condition}

To study the dynamic behavior of the typical PV system, four MPPT algorithms based on $\mathrm{P} \& \mathrm{O}$, IncCond, modified variablestep IncCond, modified IncCond sliding mode algorithm and on the proposed controller were implemented, evaluated, and compared in a Matlab/Simulink environment, taking into consideration the changes in insolation and temperature experienced by the PV system when there is a partially shaded module. There are different possibilities for the insolation and temperature among the PV array elements; the following four cases were randomly considered. The simulation results for the four cases suggest that a partially shaded module causes a reduction in PV output power. PV output power characteristics for all cases are depicted in Figure 8. 


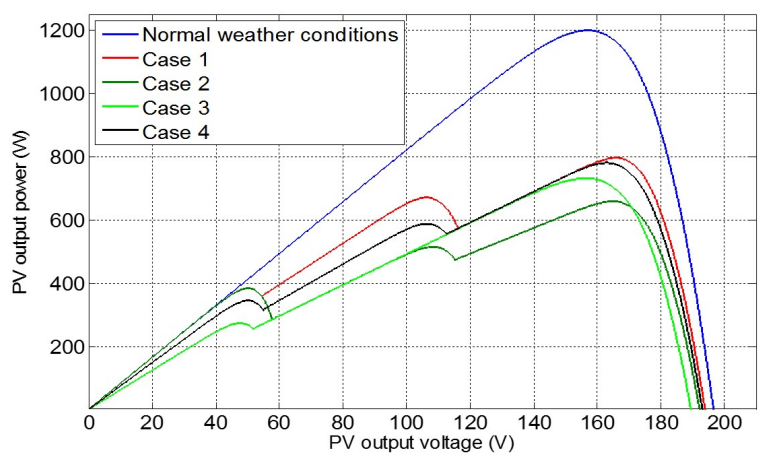

Figure 8. PV output power characteristics under different partial shade conditions (four cases).

(i) Case 1 (Test under nonuniform climatic conditions in PV module 1; constant climatic conditions in modules 2 and 3 ).

Figure 9(a) and 9(b) show insolation and temperature variations from partial shading; PV module 1 was simulated to experience these nonuniform conditions (with insolation G1 varying from 600 to, $1000 \mathrm{~W} / \mathrm{m}^{2}$, and temperature $\mathrm{T} 1$ varying from 20 to $35^{\circ} \mathrm{C}$ ), while $\mathrm{PV}$ modules 2 and 3 experienced two different sets of constant climatic conditions (PV module 2: $800 \mathrm{~W} / \mathrm{m}^{2}, 25^{\circ} \mathrm{C}$, and PV module 3: $500 \mathrm{~W} / \mathrm{m}^{2}, 40^{\circ} \mathrm{C}$ ). The dynamic response of the PV system comprising these three modules was controlled by using four techniques, as illustrated in Figure 9(c).

With reference to Figure 9(c), we observe that the response curves obtained by the proposed method, most remarkably the power curves, responded more quickly and without much oscillation, relative to two conventional methods and modified variable step IncCond technique. The $\mathrm{P} \& \mathrm{O}$ technique caused some voltage loss because its use can cause the PV system to oscillate around the maximum power point. The modified variable-step IncCond technique had more precise control and less, stable oscillation than the two conventional techniques. However, the proposed technique had the most accurate control and the least oscillation in steady state operation among the control methods tested.

(ii) Case 2 (Test under nonuniform climatic conditions in PV modules 1 and 2; constant climatic conditions in module 3)

In this case, the insolation and temperature levels simulated for PV module 3 represent shading (PV module 3: $700 \mathrm{~W} / \mathrm{m}^{2}$, $25^{\circ} \mathrm{C}$ ), and the other modules experience nonuniform atmospheric conditions (PV module 1: insolation G1 varying from 600 to $800 \mathrm{~W} / \mathrm{m}^{2}$, and temperature $\mathrm{T} 1$ varying from 22 to $30^{\circ} \mathrm{C}$; PV module 2: insolation G2 varying from 700 to $850 \mathrm{~W} / \mathrm{m}^{2}$, and temperature $\mathrm{T} 3$ varying from 25 to $44^{\circ} \mathrm{C}$ ) as shown in Figure 10(a) and 10(b). Figure 10(c) shows the dynamic response of the PV system under control by the four methods tested.

By referencing to Figure 10(c), the proposed method responded the most quickly and stably among the four methods. The conventional method and modified variable-step IncCond technique had greater oscillations and responded more slowly than the proposed method.

(iii) Case 3 (Test under nonuniform climatic conditions in PV modules 1 and 3; constant climatic conditions in module 2)

The insolation and temperature levels simulated for PV module 3 represent shading ( $\mathrm{PV}$ module 3: $600 \mathrm{~W} / \mathrm{m}^{2}, 25^{\circ} \mathrm{C}$ ), and the other modules experience nonuniform atmospheric conditions (PV module 1: insolation G1 varying from 600 to 750 $\mathrm{W} / \mathrm{m}^{2}$, and temperature $\mathrm{T} 1$ varying from 22 to $35^{\circ} \mathrm{C} ; \mathrm{PV}$ module 2: insolation $\mathrm{G} 2$ varying from 600 to $850 \mathrm{~W} / \mathrm{m}^{2}$, and temperature T3 varying from 20 to $30^{\circ} \mathrm{C}$ ) as shown in Figure 11(a) and 11(b). Figure 11(c) shows the dynamic response of the PV system under control by the four methods tested.

With reference to Figure 11(c), we observe that the response curves obtained by the proposed method, most remarkably the power curves, responded more quickly and without much oscillation, relative to two conventional methods and modified variable-step IncCond technique. The $\mathrm{P} \& \mathrm{O}$ technique caused some voltage loss because its use can cause the PV system to oscillate around the maximum power point. The modified variable-step IncCond technique had more precise control and less, stable oscillation than the two conventional techniques. However, the proposed technique had the most accurate control and the least oscillation in steady-state operation among the control methods tested.

(iv) Case 4 (Test under nonuniform climatic conditions in all PV modules)

We were interested in testing the scenario in which all PV modules experience nonuniform insolation and temperature. We report in Figures 12(a), and Figure 12(b), varying climatic conditions were simulated for each of the PV modules, including random insolation from 724 to $947 \mathrm{~W} / \mathrm{m}^{2}$ and temperature from 22 to $32^{\circ} \mathrm{C}$.; the proposed control technique clearly responded the most quickly and performed the most stably, as shown in Figure 12(c).

\subsection{Comparative Study}

All methods were able to track the global maximum power point (GMPP) with different output voltages. The proposed method 


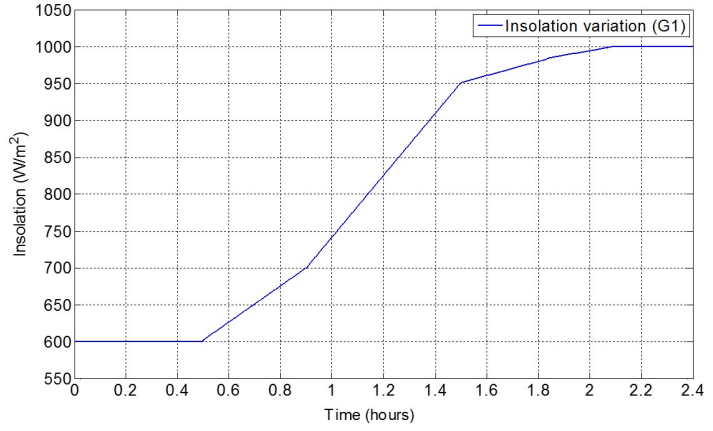

(a)

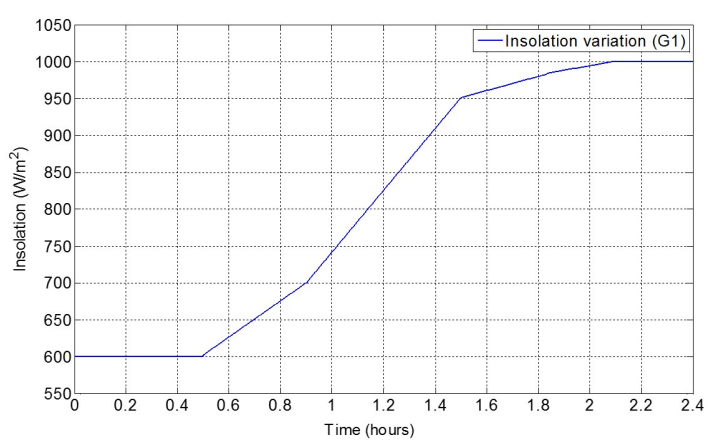

(c)

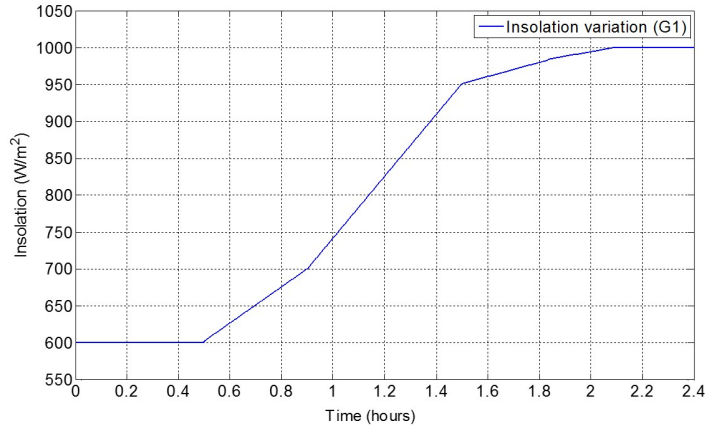

(b)

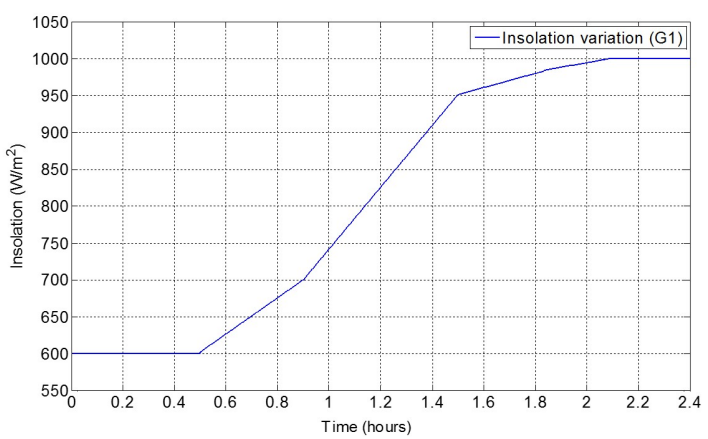

(d)

Figure 9. Influence of insolation and temperature variations (Case 1). (a) Insolation variation (G), (b) temperature variation (T1), (c) PV power response to the variations under five control schemes, and (d) zoom of PV power.

showed more robustness in terms of its dynamic behavior under different operating conditions, such as nonuniform insolation and temperature, than the conventional methods evaluated

Tables 2-5 show comparative assessment of five MPPT techniques. The performance is accessed in terms of energy produced by PV array; the oscillation in power at time $t=0.5 \mathrm{sec}$, the response times to achieve the MPP. From the Table results, the proposed MPPT technique works quit well where as their performance degrades as compared to other MPPT algorithms. The proposed method worked well under varying conditions of nonuniform insolation and temperature, with less oscillation and faster response. The efficiency of the proposed scheme in such conditions was demonstrated by means of simulations. The proposed method provided more stable operation, greater reliability and feasibility, and faster response than two conventional MPPT techniques and modified variable-step IncCond MPPT. The main advantages of the technique developed herein are its fast convergence to the MPP, its robustness, its higher efficiency, and the possibility of easy implementation.

We considered the influence of non-uniform insolation and temperature on all PV modules to evaluate their performance.
Figures 9(c), 10(c), 11(c) and 12(c) show the output power of the three methods under partially shaded conditions. All methods were able to track the GMPP with different output voltages. Specifically, the proposed method was characterized by a small oscillation when the MPP was reached, whereas other methods have more oscillation and overshoot around the GMPP. The proposed method showed more robustness in terms of its dynamic behavior under different operating conditions, such as non-uniform insolation, non-uniform temperature, and resistive load, than the conventional methods evaluated.

\section{Conclusions}

Generation of output power from a PV system is dependent on weather conditions. The performance of different MPPT methods used in the PV system was critically assessed under nonuniform atmospheric conditions. The performance of the proposed modified perturb and observe sliding MPPT technique was compared with that of conventional MPPT methods and modified variable-step IncCond MPPT method under varying solar insolation and temperature conditions corresponding to cloudy 


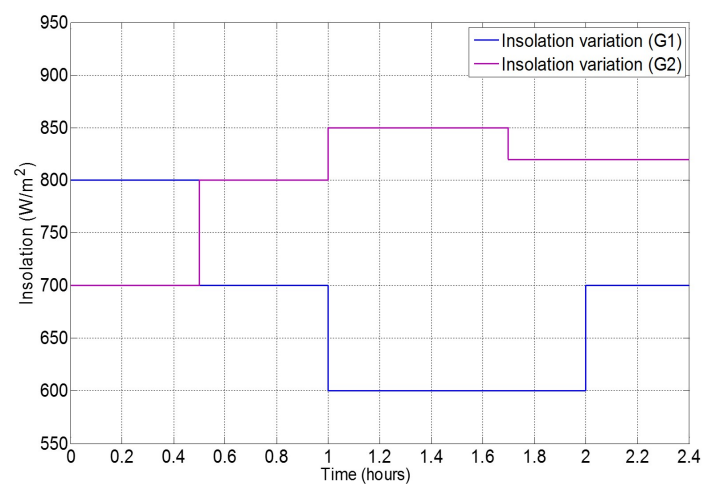

(a)

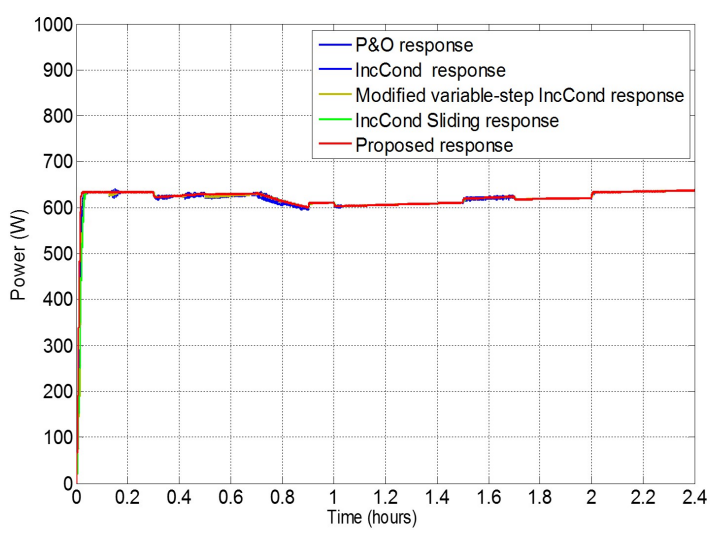

(c)

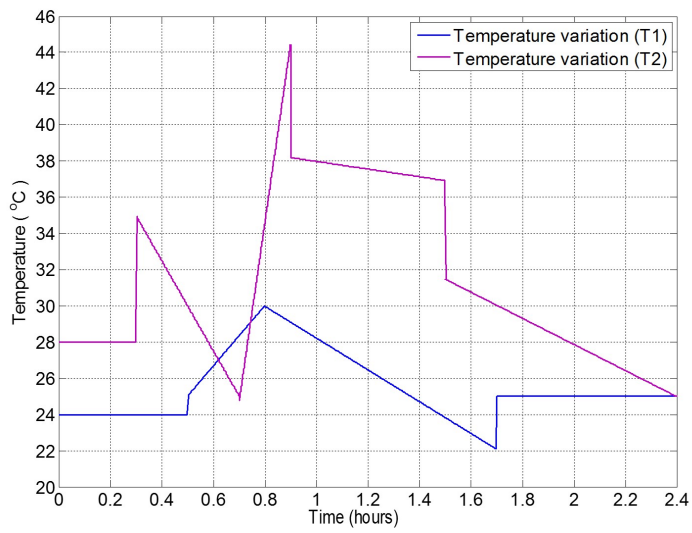

(b)

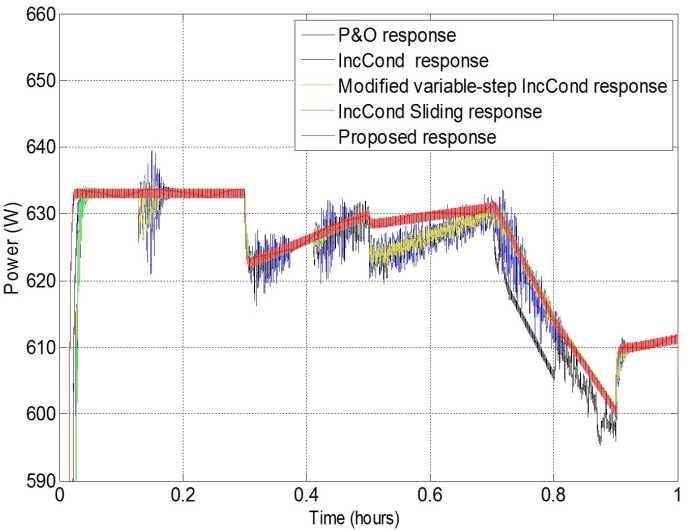

(d)

Figure 10. Influence of insolation and temperature variations (Case 2). (a) Insolation variation (G), (b) temperature variation (T1), (c) PV power response to the variations under five control schemes, and (d) zoom of PV power.

Table 2. Comparative assessment of different MPPT algorithms at Case 1

\begin{tabular}{ccc}
\hline Algorithms & Oscillation around MPP (W) & Response time (s) \\
\hline Perturb and observe & 6.8 & 0.064 \\
\hline IncCond & 8.4 & 0.094 \\
Modified variable-step IncCond & 6.1 & 0.094 \\
Modified ICS & 0.9 & 0.058 \\
\hline Proposed & 0.9 & 0.051 \\
\hline
\end{tabular}

ICS, incremental conductance sliding.

weather. Simulation results were performed, showing that the conventional MPPT techniques and modified variable-step IncCond MPPT performed reasonably well under nonuniform atmospheric conditions. However, the use of these techniques tends to cause oscillations of the PV array operating point at MPP under rapidly changing conditions of partial shading and temperature. The modified variable-step IncCond MPPT algorithm performed more efficiently in response to rapidly changing atmospheric conditions, and was more stable during MPP tracking, compared with the conventional algorithms. The proposed algorithm converged rapidly with little oscillation around the MPP during steady state and response time than the other 


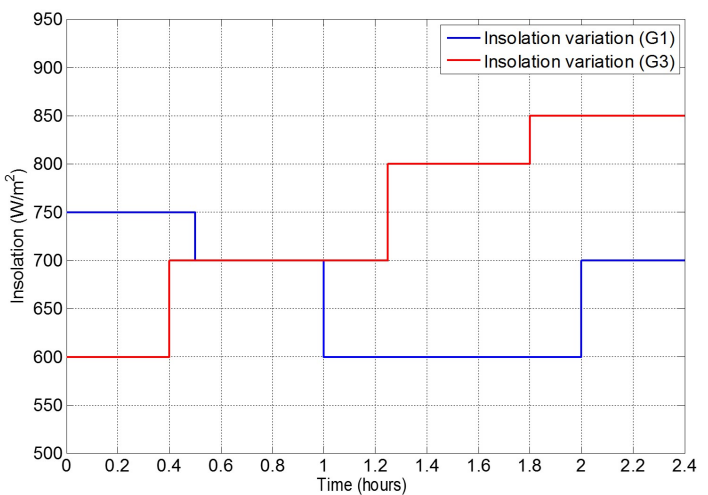

(a)

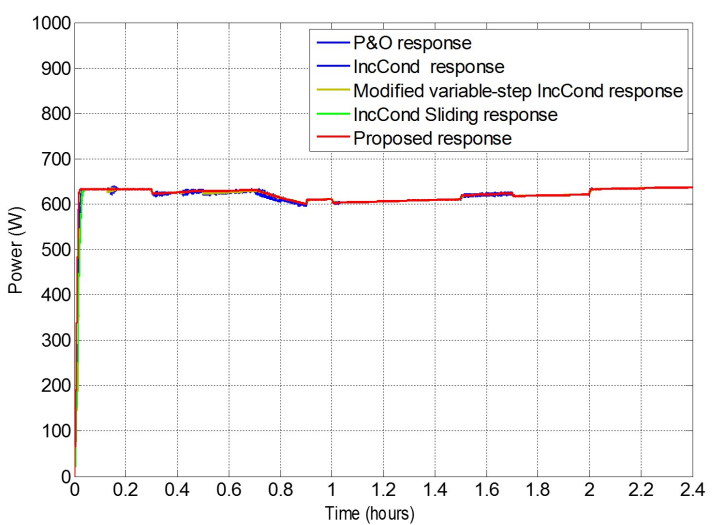

(c)

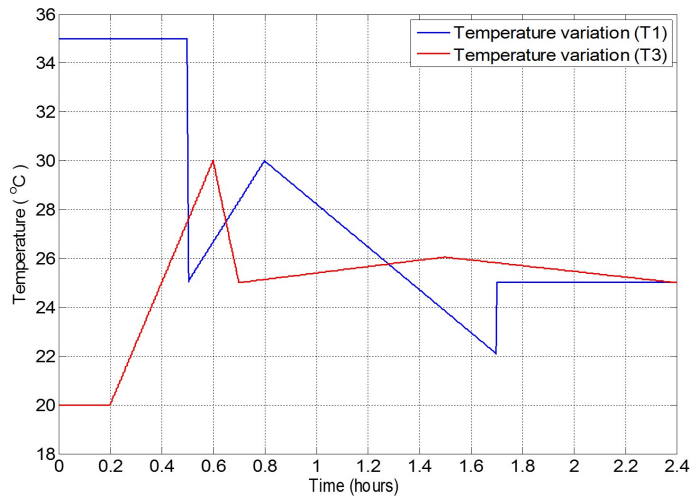

(b)

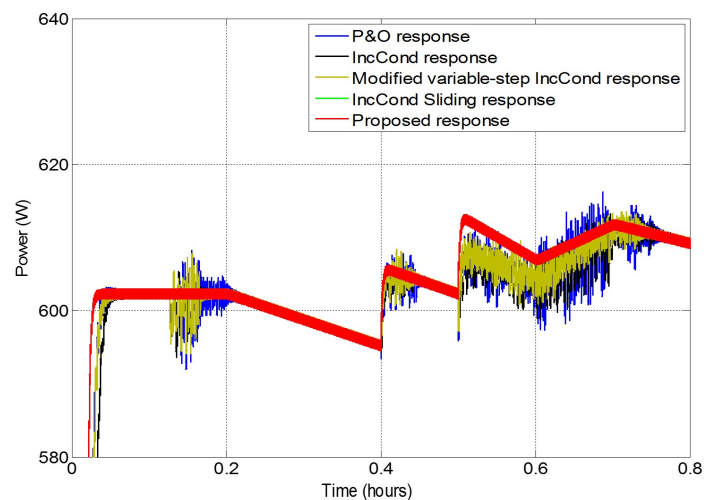

(d)

Figure 11. Influence of insolation and temperature variations (Case 3). (a) Insolation variation (G), (b) temperature variation (T1), (c) PV power response to the variations under five control schemes, and (d) zoom of PV power.

Table 3. Comparative assessment of different MPPT algorithms at Case 2

\begin{tabular}{ccc}
\hline Algorithms & Oscillation around MPP (W) & Response time (s) \\
\hline Perturb and observe & 10.2 & 0.032 \\
\hline IncCond & 8.9 & 0.046 \\
Modified variable-step IncCond & 7.9 & 0.044 \\
Modified ICS & 1.4 & 0.039 \\
\hline Proposed & 1.4 & 0.021 \\
\hline
\end{tabular}

ICS, incremental conductance sliding.

four algorithms. Matlab based simulations of a PV system with MPPT control were perform to validate the proposed method.

\section{Conflict of Interest}

No potential conflict of interest relevant to this article was reported.

\section{References}

[1] J. Hahm, H. Kang, J. Baek, H. Lee, and M. Park, "Design of incremental conductance sliding mode MPPT control applied by integrated photovoltaic and proton exchange membrane fuel cell system under various operating conditions for BLDC motor," International Journal of Photoenergy, vol. 2015, article ID. 828129, 2015. 


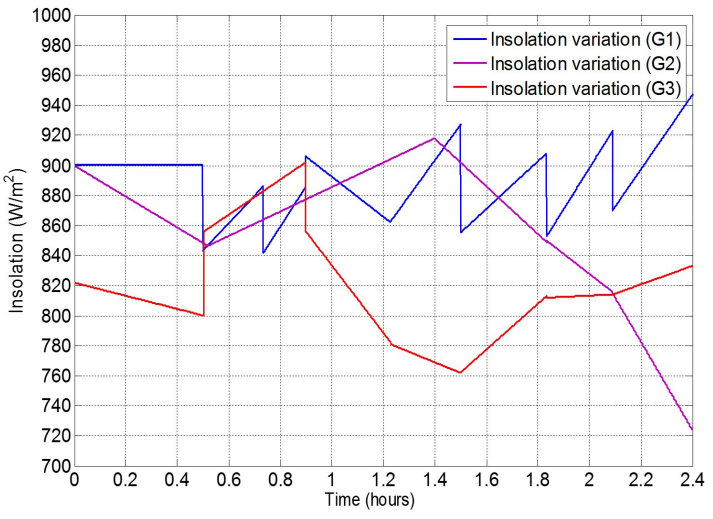

(a)

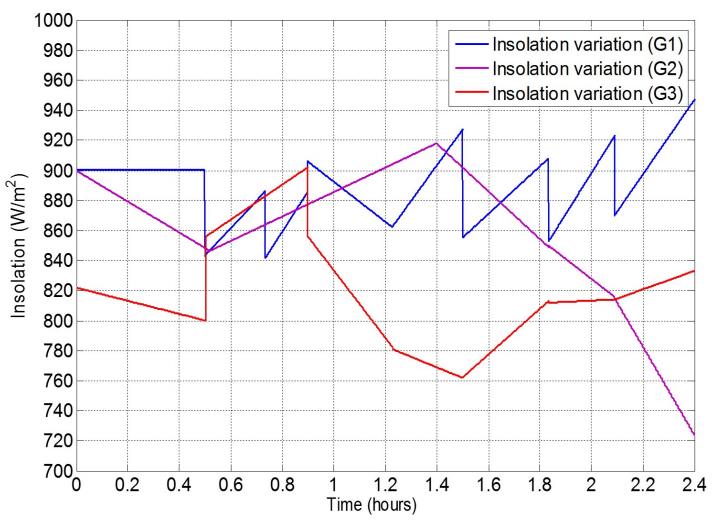

(c)

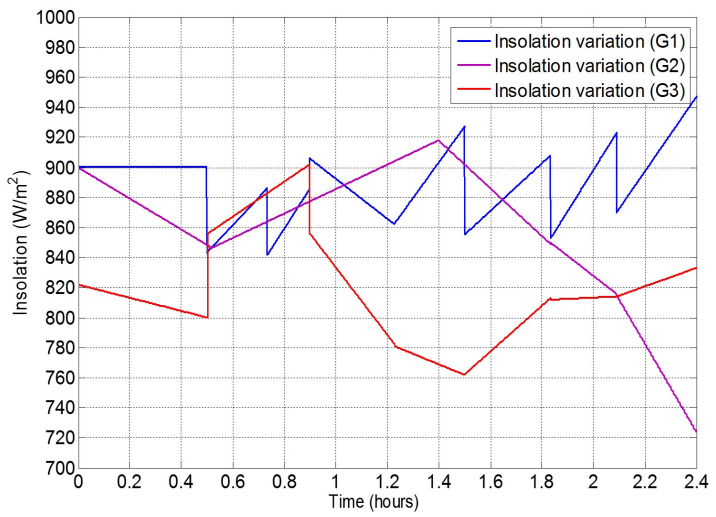

(b)

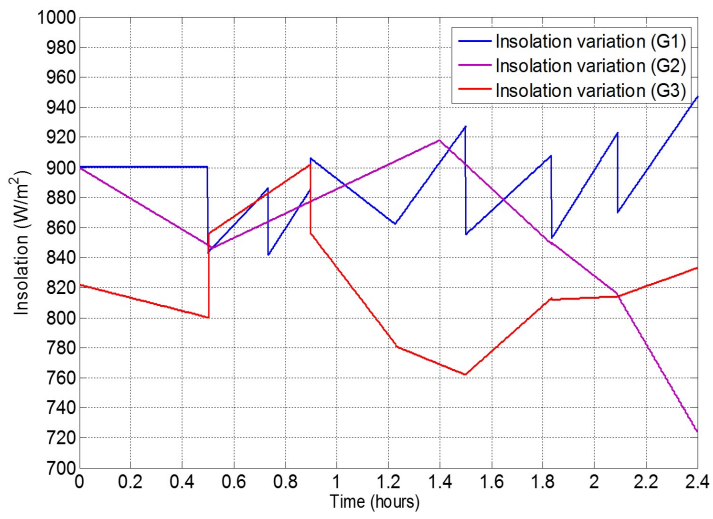

(d)

Figure 12. Influence of insolation and temperature variations (Case 3). (a) Insolation variation (G), (b) temperature variation (T1), (c) PV power response to the variations under five control schemes, and (d) zoom of PV power.

Table 4. Comparative assessment of different MPPT algorithms at Case 3

\begin{tabular}{ccc}
\hline Algorithms & Oscillation around MPP $(\mathrm{W})$ & Response time $(\mathrm{s})$ \\
\hline Perturb and observe & 3.0 & 0.040 \\
\hline IncCond & 2.7 & 0.049 \\
Modified variable-step IncCond & 2.5 & 0.042 \\
Modified ICS & 0.5 & 0.032 \\
\hline Proposed & 0.5 & 0.032 \\
\hline
\end{tabular}

ICS, incremental conductance sliding.

http://dx.doi.org/10.1155/2015/828129

[2] J. Hahm, J. Baek, H. Kang, H. Lee, and M. Park, "Matlabbased modeling and simulations to study the performance of different MPPT techniques used for photovoltaic systems under partially shaded conditions," International Journal of Photoenergy, vol. 2015, article ID. 979267, 2015. http://dx.doi.org/10.1155/2015/979267
[3] K. Branker, M. J. M. Pathak, and J. M. Pearce, "A review of solar photovoltaic levelized cost of electricity," Renewable and Sustainable Energy Reviews, vol. 15, no. 9, pp. 4470-4482, 2011. http://dx.doi.org/10.1016/j.rser.2011.07. 104

[4] J. O. Jaber, Q. M. Jaber, S. A. Sawalha, and M. S. Mohsen, "Evaluation of conventional and renewable energy sources 
Table 5. Comparative assessment of different MPPT algorithms at Case 4

\begin{tabular}{ccc}
\hline Algorithms & Oscillation around MPP $(\mathrm{W})$ & Response time $(\mathrm{s})$ \\
\hline Perturb and observe & 10.8 & 0.053 \\
\hline IncCond & 10.3 & 0.467 \\
Modified variable-step IncCond & 10.3 & 0.475 \\
Modified ICS & 4.7 & 0.021 \\
Proposed & 4.7 & 0.021 \\
\hline
\end{tabular}

ICS, incremental conductance sliding.

for space heating in the household sector," Renewable and Sustainable Energy Reviews, vol. 2, no. 1, pp. 278-289, 2008. http://dx.doi.org/10.1016/j.rser.2006.05.004

[5] W. C. Lattin and V. P. Utgikar, "Transition to hydrogen economy in the United States: a 2006 status report," International Journal of Hydrogen Energy, vol. 32, no. 15, pp. 3230-3237, 2007. http://dx.doi.org/10.1016/j.ijhydene. 2007.02.004

[6] J. H. R. Enslin, M. S. Wolf, D. B. Snyman, and W. Swiegers, "Integrated photovoltaic maximum power point tracking converter," IEEE Transactions on Industrial Electronics, vol. 44, no. 6, pp. 769-773, 1997. http://dx.doi. org/10.1109/41.649937

[7] G. Rizzo, I. Arsie, and M. Sorrentino, "Solar energy for cars: perspectives, opportunities and problems," in Proceedings of GTAA Meeting, Mulhouse, France, 2010.

[8] D. K. Ross, "Hydrogen storage: the major technological barrier to the development of hydrogen fuel cell cars," Vacuum, vol. 80, no. 10, pp. 1084-1089, 2006. http://dx. doi.org/10.1016/j.vacuum.2006.03.030

[9] S. M. Diamond and M. G. Ceruti, "Application of wireless sensor network to military information integration," in Proceedings of 2007 5th IEEE International Conference on Industrial Informatics, Vienna, Austria, 2007, pp. 317322. http://dx.doi.org/10.1109/INDIN.2007.4384711

[10] B. C. Mecrow and A. G. Jack, "Efficiency trends in electric machines and drives," Energy Policy, vol. 36, no. 12, pp. 4336-4341, 2008. http://dx.doi.org/10.1016/j.enpol.2008. 09.042

[11] R. A. Smith, "Enabling technologies for demand management: transport," Energy Policy, vol. 36, no. 12, pp. 44444448, 2008. http://dx.doi.org/10.1016/j.enpol.2008.09.072
[12] W. Hong, W. Lee, and B. K. Lee, "Dynamic simulation of brushless DC motor drives considering phase commutation for automotive applications," in Proceedings of 2007 IEEE International Electric Machines \& Drives Conference, Antalya, Turkey, 2007, pp. 1377-1383. http://dx.doi.org/10.1109/IEMDC.2007.383630

[13] P. Pillay and R. Krishnan, "Modeling, simulation, and analysis of permanent-magnet motor drives. II. The brushless DC motor drive," IEEE Transactions on Industry Applications, vol. 25, no. 2, pp. 274-279, 1989. http: //dx.doi.org/10.1109/28.25542

[14] X. Sun, W. Wu, B. Wang, and X. Wei, "A research on photovoltaic energy controlling system," in Proceedings of the 5th International Conference on Electrical Machines and Systems, Shenyang, China, 2001, pp. 542-545. http: //dx.doi.org/10.1109/ICEMS.2001.970731

[15] M. C. Glass, "Improved solar array power point model with SPICE realization," in Proceedings of the 31st Intersociety Energy Conversion Engineering Conference, Washington, DC, 1996, pp. 286-291. http://dx.doi.org/10. 1109/IECEC.1996.552886

[16] S. J. Kim, B. M. Kim, and S. H. Kim, "Design of CRIObased real-time controller for small-sized wind turbine generating system and comparative study on performance of various MPPT algorithms," Journal of Korean Institute of Intelligent Systems, vol. 21, no. 1, pp. 55-61, 2011. http://dx.doi.org/10.5391/JKIIS.2011.21.1.55

[17] F. Asghar, M. Talha, and S. H. Kim, "Development of energy management system for micro-grid with photovoltaic and battery system," Journal of Korean Institute of Intelligent Systems, vol. 25, no. 3, pp. 299-305, 2015. http://dx.doi.org/10.5391/JKIIS.2015.25.3.299 
[18] T. Tafticht, K. Agbossou, M. L. Doumbia, and A. Cheriti, "An improved maximum power point tracking method for photovoltaic systems," Renewable Energy, vol. 33, no. 7, pp. 1508-1516, 2008. http://dx.doi.org/10.1016/j.renene. 2007.08.015

[19] S. J. Seo, D. W. Kim, and G. T. Park, "Design of adaptive fuzzy sliding mode controller for chattering reduction," Journal of Korean Institute of Intelligent Systems, vol. 14, no. 6, pp. 752-758, 2004. http://dx.doi.org/10.5391/JKIIS. 2004.14.6.752

[20] S. M. Alghuwainem, "Matching of a dc motor to a photovoltaic generator using a step-up converter with a currentlocked loop," IEEE Transactions on Energy Conversion, vol. 9, no. 1, pp. 192-198, 1994. http://dx.doi.org/10.1109/ 60.282492

[21] W. Xiao, W. G. Dunford, and A. Capel, "A novel modeling method for photovoltaic cells," in Proceedings of 2004 IEEE 35th Annual Power Electronics Specialists Conference, Aachen, Germany, 2004, pp. 1950-1956. http://dx.doi.org/10.1109/PESC.2004.1355416

[22] J. A. Gow and C. D. Manning, "Development of a photovoltaic array model for use in power-electronics simulation studies," IEE Proceedings-Electric Power Applications, vol. 146, no. 2, pp. 193-200, 1999. http://dx.doi.org/ 10.1049/ip-epa:19990116

[23] W. De Soto, S. A. Klein, and W. A. Beckman, "Improvement and validation of a model for photovoltaic array performance," Solar Energy, vol. 80, no. 1, pp. 78-88, 2006. http://dx.doi.org/10.1016/j.solener.2005.06.010

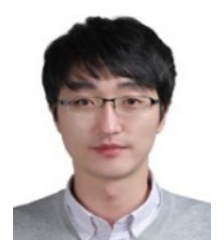

Jehun Hahm received a B.S. degree in electrical engineering from the Seoul National University of Science Technology, Seoul, Korea in 2008. He is candidate of Combined Master's and Doctoral Program in new energy and battery engineering from Yonsei University, Seoul, Korea. His main research interests include photovoltaic systems, fuel cell systems, and control of fuzzy systems. Since 2016, he has been a senior research engineer in Korea Institute of Robot and Convergence.

E-mail: jhham@yonsei.ac.kr

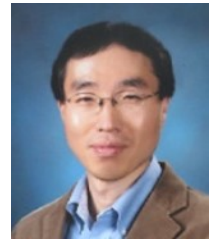

Euntai Kim was born in Seoul, Korea, in 1970. He received B.S., M.S., and Ph.D. degrees in Electronic Engineering, all from Yonsei University, Seoul, Korea, in 1992, 1994, and 1999, respectively. From 1999 to 2002 , he was a Full-Time Lecturer in the Department of Control and Instrumentation Engineering, Hankyong National University, Ansung, Korea. Since 2002, he has been with the faculty of the School of Electrical and Electronic Engineering, Yonsei University, where he is currently a Professor. He was a Visiting Scholar at the University of Alberta, Edmonton, AB, Canada, in 2003, and also was a Visiting Researcher at the Berkeley Initiative in Soft Computing, University of California, Berkeley, CA, USA, in 2008. His current research interests include computational intelligence and statistical machine learning and their application to intelligent robotics, unmanned vehicles, and robot vision.

E-mail: etkim@yonsei.ac.kr

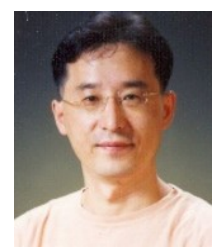

Heejin Lee was born in Seoul, Korea, in 1964. He received the B.S., M.S., and Ph.D. degrees in electronic engineering, all from Yonsei University, Seoul, Korea, in 1987, 1989, and 1998, respectively. He was a Researcher in Daewoo Telecom Ltd., Seoul, Korea, from 1989 to 1993. He is currently a Professor in the Department of Electrical, Electronic and Control Engineering, Hankyong National University, Ansung, Korea. His current research interests include fuzzy control theory, fuzzy application system, adaptive and robust control, robotics, and automation.

E-mail: lhjin@hknu.ac.kr

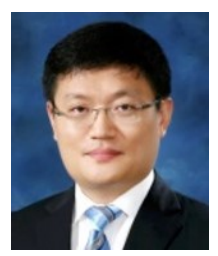

Changyong Yoon received B.S., M.S., and $\mathrm{Ph} . \mathrm{D}$. degrees in Electrical and Electronic Engineering from Yonsei University, Seoul, Korea, in 1997, 1999, and 2010, respectively. He was a senior research engineer in LG Electronics, Inc., and LG-Nortel, and he developed system software for the DVR and WCDMA from 1999 to 2006. From 2010 to February 2012, he was a chief research engineer in LG Display and developed the circuit and algorithms in touch systems. Since 2012, he has been a Professor in the Department of Electrical Engineering, Suwon Science College, Hwaseong, Korea. His main research interests include intelligent transportation systems, pattern recognition, robot vision, and fuzzy application systems.

E-mail: cyyoon@ssc.ac.kr 